\title{
Lab Notes
}

\section{Reaching Out: Working with Teachers and Faculty}

\author{
by David Pankratz, Loyola University Chi- \\ cago, Marie Sheppard/Robin McClanahan, \\ University of Colorado at Boulder
}

[Editor's Note: This paper is based on a presentation with the same title made at the IALL '93 Conference at the University of Kansas. The presentation was given in a Focus Session on the topic of teacher/faculty training. Three presenters (David Pankratz, Theresa Johnson, and Robin McClanahan for Marie Sheppard) reported on the strategies they have used to get faculty more involved in using new technologies and materials for foreign language learning and teaching. Their reports were preceded by an introduction and followed by discussion among the members of the audience. Unfortunately, we were not able to obtain the paper of one of the presenters. However, the introduction and presentations by David Pankratz and Marie Sheppard/Robin McClanahan are included here as a companion piece to "Narrowing the Pedagogy-Technology Gap" in this issue.]

\section{Introduction to the Panel Session}

I believe that faculty training is one of the most important areas in which we as language lab professionals should become involved. Faculty need to be aware of the available technologies and materials and then actively exploit them in their teaching in order to provide students the best support possible.

I think that many language lab directors already recognize that this is an area in which they need to develop some degree of expertise. Who will take the lead in educating the faculty in language lab technologies if lab directors do not? 
"Who will take the lead in educating the faculty in language lab technologies if lab directors do not?!"
Language lab personnel are the best resources for bringing faculty up-to-date on emerging technologies and learning materials in foreign language pedagogy.

The concept of "faculty training" need not sound strange or intimidating - most lab directors already engage in faculty training on a day-to-day basis through hands-on assistance and suggestions. The issue to be addressed here, then, is how we might make our attempts to convey information more focused, more systematic, and more effective.

Most of us feel that the faculty at our respective institutions could be more actively using all the new technologies, AV materials, and software programs. Are we assuming that they are aware of all these new things? Are we assuming that they know how valuable these things can be to their teaching? I don't think we should make these assumptions. For example, many teachers do not have an understanding of what such terms as "CD-ROM" or "interactive programs" really signify. There are others who do understand the fundamentals of these technologies and programs, but have no practical ideas for how to go about using them. Regardless of the reasons why faculty are not using the new technologies and materials, it is one of the lab director's responsibilities to facilitate the process.

It may be difficult for us to accept this role of having to "educate" faculty, but I think we will begin to see more support and encouragement from all levels. I would like to quote from an article written by Robert Quinn, associate professor and chair of the Modern Language Department at Millsaps College. His article, "Opening the Doors of the Language Laboratory: New Perspectives \& Opportunities," is one of a series of articles making up a special issue of the ADFL Bulletin entitled "Chairing the Foreign Language and Literature Department." In this article he outlines the important role of the language lab and the lab director from the perspective of department chairs. He writes,

One of the most important aspects of implementing technologically assisted instruction-yet one of the most neglected-is the training of faculty members. Merely having an authoring system that lets teachers produce computer-assisted lessons rapidly, for instance, does not necessarily ensure that they will write effective lessons. Teachers have to know the basic purposes for each of the media and the proper techniques for using the laboratory equipment before they can use authoring software appropriately. 
In his article he also writes about the merits of computer programs versus audio programs, and how lab directors need to help faculty determine which media are best for specific teaching objectives. Quinn also comments on the significance of the lab director in this area. He writes,

To capitalize on the potential of the media and facilitate the coordination of coursework and labwork, it is essential to have a reliable, experienced lab director. This staff member must deal with numerous details like training new faculty in the use of the media, orienting new students....

It is very interesting to note that "training new faculty" is the first item on his list of job responsibilities for a lab director. He sees it as the foremost responsibility of someone in this position. I would add, and I think he would agree, that training is not only important for new faculty, but for all faculty due to the ongoing evolution of technologies. His statements are important because they are an indication of a discussion taking place among department chairs who are beginning to understand more clearly the need for providing training for their faculty, and the role of the lab director in this process.

There are, of course, many barriers which prevent faculty from integrating more technologies into the curriculum. They may not have found the time to become familiar with the specific audio-visual programs relevant to the subject matter they teach. Or, they may feel vulnerable working with equipment they are not at ease with-after all, they are accustomed to being the experts in the eyes of others, not amateurs! Some

"Some may have what I would call a general sort of 'techno-angst,' believing that the equipment will selfdestruct if they make one wrong move!" may have what I would call a general sort of "techno-angst," believing that the equipment will self-destruct if they make one wrong move! And of course in some cases there is a barrier of a different nature, the conviction that all this new technology is simply taking students away from the basics of rote reading, writing, studying and memorizing. No matter what the barriers may be, we have the challenge to try to break them down bit by bit.

It may be helpful to see the process of faculty training in four stages: informing, providing training, facilitating integration into the curriculum, and follow-up.

First, faculty must be aware that the lab has something to offer them and their students. We have to inform them. For example, do all your faculty know about that new computer program in your lab that may be just right for the course they will be teaching next fall? Do they know that you would be 
"From my experience the only real way to ensure that students will actually use lab materials, for example, is to require their use as part of the course." happy to show it to them, if only you could agree on a time? Do they know that some of their more explorative students are already using the program, and that all they as instructors have to do to add it to their course syllabus is gain some familiarity with the program. How are you going to contact them and raise these questions?

Next, how will you go about providing training? One-onone? Small group workshops? Helping to sign them up for a workshop given by another department on campus? There are many possibilities, some of which will be discussed here.

After training has been provided, how can you help facilitate the actual integration of what instructors have learned into their curriculum? It doesn't do much good if faculty are informed and even enthusiastic, but fail to integrate the new technologies into their teaching or otherwise encourage their students to use the materials. From my experience the only real way to ensure that students will actually use lab materials, for example, is to require their use as part of the course. The instructor-not the lab-must set up monitoring mechanisms, such as having students discuss the content of the lab material in class, or giving them exercises or quizzes based on the material.

Finally, follow-up is essential. How do we know if we've been successful in actually increasing the use of audio-visual and lab technologies and materials? How do we monitor and maintain usage?

The following report discusses a series of small-group workshops I offered to faculty at Loyola University Chicago. I hope this will give you ideas and motivate you to try something new to increase faculty awareness and involvement at your school.

\section{Designing Small- Group Workshops}

by David Pankratz

Introduction

The Survey
In fall 1992, I perceived a need for some type of development activities that would familiarize faculty with our newly renovated language lab. I wanted to reach faculty who had not yet become familiar with some of the most basic technologies, such as using a VCR or word processing. I also hoped to stimulate those who were already well-versed in using video and computers to make increased use of those media.

I decided to offer a series of small-group workshops. I felt this would be a personable, non-threatening approach to bridging some of the gaps in the instructors' awareness and understanding of a few key technologies.

Because I wanted to base workshop topics on areas of most interest to faculty, I decided to collect information with a 
written survey. There were several reasons for taking this approach. First, a survey is informative not only for the person collecting the data, but can be equally informative for those responding to it. Through the questions, readers are made aware of learning possibilities by the survey writer. In this way, surveys are informational without being pedantic. Second, surveys are by nature interactive. Instead of merely reading another piece of informational literature, respondents must actively think and commit their responses to writing. To stimulate this interaction, I like to include some open-ended questions and a section for general comments. Finally, surveys can be designed to gather information not obviously related to the main topic. For example, I asked what time of day, what day of the week, etc., would be best for attending workshops. I also asked who felt qualified and interested in acting as a co-presenter for workshops.

In my survey I presented a "menu" of possible workshop topics, and in each case asked the respondents to indicate their interest on a $1-5$ scale. There was space for comments, and a section to indicate if they would like to serve as a co-presenter for a workshop on that topic. Proposed workshop topics were:

- Audio

- Equipment in lab, creative use of the equipment for individuals and small groups (At Loyola, we have no console lab.)

- Creative use of audio in the classroom

- Video

- Technical know-how, e.g., using real-time counters, multi-standard equipment, etc.

"First, a survey is informative not only for the person collecting the data, but can be equally informative for those responding to it."

- Creative use of video in the classroom

- Computer

- Word processing with "WordPerfect"

- Beginning-level foreign language programs/drills for students

- Software for advanced language students

- Macintosh computers and software (new to us at the time)

- Having lab staff develop computer drills for students based on faculty input

- Using the campus computer network to access the library's on-line catalog

- Electronic mail

- Interactive

- Demonstrations of commercially available programs

- Demonstrations of locally developed programs (not many!)

-Developing programs 
Within the survey I elaborated briefly on my own definition of "interactive programs." As mentioned earlier, this was an example of how the survey was information-disseminating as well as information-gathering.

The Workshops Response to the written survey was good: about $75 \%$ of faculty responded. I synthesized the results of the survey and decided on workshop topics based on those results.

Faculty were primarily interested in four areas: using video in the classroom, instructional computer programs for their students, word processing, and using the university network to access the library catalog and take advantage of electronic mail. The first two areas were what we might call studentcentered: the goal was to improve direct services to students. The last two were definitely faculty-centered: faculty were interested in furthering their own expertise in use of the computer, even if that meant simply sharpening word processing skills-or developing them for the first time!

Each workshop was offered twice in order to accommodate differing schedules. I scheduled one session at the end of a day when most faculty were already on campus, and another on a day when most faculty did not teach and might have the time-and energy - to attend. As it turned out, the preferred times were in the afternoons on those days when most faculty were already on campus.

I sent out workshop registration forms to the faculty and asked them to return them to me with their choices. There was no fee for the workshops.

For each workshop I asked one faculty member to help me by acting as a co-presenter. At least two weeks prior to a given workshop, I met with this person and discussed the goals of the workshop, what I would do, and what I would like to have them do. I cannot overstate the important role these copresenters played. All of us learned from each other, and the faculty as co-presenters gave the sessions an informal feel that I would not have been able to create on my own.

Each workshop was scheduled for one hour. I knew that I had more material than I could realistically cover in that time, but I also sensed that faculty would not commit more than one hour of their time. Most workshops did run a little longer, but almost everyone stayed the extra time. Cookies were served at every session. Many lab directors had told me that food was a great magnet, but equally important was the pickme-up and conversation starter that a little snack provided before getting serious about the day's topic. 
The content of the workshops was designed to be as practical as possible, but not altogether devoid of theory. For example, in the session on using video I started by outlining some of the major principles in designing good video lessons before moving on to showing sample activities that could be used in the classroom. Using pre-workshop participants as students, the co-presenter demonstrated several video-based activities she uses in class. In the session on using the computer network, the focus on how to receive and send electronic mail was prefaced by a brief introduction to local email, the Internet, discussion lists, etc. These theoretical discussions gave the faculty the sense that their responsibilities lie not only in learning the hands-on, nuts-and-bolts procedures for using the technologies, but also in examining the pedagogical and research-related issues behind them.

Workshops were moderately well attended-between three and six participants per session. At first I was a little disappointed, but then concluded that reaching people intensively in a small group was more satisfying and probably more productive than speaking to a larger group would have been. I felt it was important not to get discouraged by the small numbers.

Follow-up Following each workshop, I sent a note to the co-presenter to thank him/ her. When the entire workshop series was finished, I sent a report summarizing which workshops had been offered, names of co-presenters, and the number of participants to my supervisor and a copy to the dean. I met with the LLRC committee to report on the successes and plan a future strategy.

"...Our effort may ex-

The more difficult follow-up task was to assess how each press itself not merely in an increase in the quantity of time that students spend in the lab, but also in the quality of their time." of the participants and ultimately their students were affected. I contacted faculty who had attended and asked them informally if they had tried anything new as a result of the workshop. I tried to encourage them and make a few suggestions based on their course objectives and individual "comfort level." I also tried to observe changes in numbers and patterns of students coming to the lab to do individualized video and computer work. In some cases I did notice an increase.

When assessing the impact of faculty development activities such as workshops, I feel it is important to keep in mind that our effort may express itself not merely in an increase in the quantity of time that students spend in the lab, but also in the quality of their time. For this reason I felt it was important to begin to more carefully document what students were actually doing in the lab and not just how long they were there. 
I sense that we as lab directors sometimes focus too much on quantitative data and neglect to elaborate that our lab services have improved qualitatively as well. Many students are learning foreign language more effectively from using interactive programs than they would be if they were spending the same amount of time in an audio carrel. Their ability to use these more complicated programs and technologies is to a large extent due to our work.

The greatest satisfaction following the workshops came at our next faculty meeting. The chairperson for the Modern Languages \& Literatures Department, who is also my supervisor, announced that learning about the new technologies was "no longer an option, but a must" for foreign language faculty. This was the first time that I had heard such a direct statement come from the department chair. I felt that his statement was due, at least in part, to a raising of awareness that had been accomplished through the workshops.

Works Cited

Quinn, Robert A. "Opening the Doors of the Language Laboratory: New Perspectives and Opportunities." Chairing the Foreign Language and Literature Department. A Special issue of the ADFL Bulletin. Ed.Bugliani. 25.3 (1994): 81 - 86.

\section{ALTEC's Liaison \\ Program}

by Marie Sheppard and Robin McClanahan

\author{
Who are the Liaisons?
}

After some trial and error, we realized the liaison program works best if the person selected to be the liaison is either a graduate student or an instructor in the department that the faculty have selected (with our approval). The faculty need to feel that the liaison is a colleague and can be trusted to represent their interests.

There are five language departments at the University of Colorado at Boulder that we serve: Spanish and Portuguese, French and Italian, Germanic and Slavic, Oriental, and Classics. We also serve the language section of Continuing Education and will soon support English as a Second Language. We 


\section{Qualifications}

\section{Liaison Job Description and Typical Projects}

"The faculty need to feel that the liaison is a colleague and can be trusted to represent their interests." almost always hire three "permanent" liaisons (Spanish, French, German) and we may hire one or two more that will represent different languages based on need.

Teaching experience is a must; however, teaching during employment is not necessary (although a plus). As mentioned previously, the prospective liaison should currently be a graduate student or an instructor in the foreign language department that they will represent. (It is interesting to note that the people interested in being the liaison tend to be women with very young children - probably because they need a flexible working environment, and we are very willing to be accommodating.) Again, the prospective liaison must be approved by the foreign language department (ask the faculty for suggestions after careful explanation of the position).

We do not require that the liaisons have technical experience with computers and other equipment such as scanners or LCD panels, but they at least must not be afraid of the equipment and must be willing to learn quickly. Native speaker status is very valuable but also is not required.

The liaisons work approximately ten hours per week and are paid about ten dollars per hour. They are provided with an ALTEC office (which they share with one or two other liaisons) complete with telephone, computer and filing space. We give them keys to the building and to ALTEC, and they may choose their own work hours. Every two weeks the liaisons give the director a report of their activities, and all the liaisons meet together with the director once per month.

The things that the liaisons do on a daily and weekly basis are numerous and varied. Below are a few examples in no particular order:

- Familiarize themselves with all materials available at ALTEC for their language

- Report on ALTEC activities/materials to their departments

- Evaluate materials that ALTEC is considering for purchase

- Put materials into professional form (such as compiling a workbook)

- Prepare materials (such as organizing Hanzi Assistant by chapter to correspond with the text; entering verbs in Spanish Tense Tutor)

- Screen satellite materials (such as TV-5 and SCOLA) and make selections

- Assist with proposal writing

- Act as an advocate from their department to ALTEC and vice versa (look out for theinterest of their own department atALTEC) 
- Visit all foreign language faculty at least once per semester

- Identify curriculum-revision projects for individual faculty members (Liaisons have credibility because they are teachers!)

- Edit videos for faculty members

- Help students occasionally with special projects (such as e-mail exchanges)

- Establish exchange programs

- Provide valuable feedback to ALTEC director (They tend to suggest things that undergraduates don't.)

- Watch "lists" on the network

- Compile "use" lists-who is using what in the departments

- Conduct surveys-how is ALTEC meeting people's needs?

- Conduct end-of-semester visits to course coordinators (Are they changing texts?)

- Promote scheduled workshops/seminars

- Review/update ALTEC catalog of materials

- Participate in fund-raising from corporations

- Act as ALTEC advocate at the University level and in the community

- Give tours of ALTEC and language-specific workshops

- Perform errands (such as going to the bank to exchange currency)

- Evaluate off-satellite recording and make selections for individual faculty members

- Design materials (e.g. support materials for French in Action, Puntos de partida)

- Organize language groups (Japanese)

- Work with student language clubs and Club Coordinator from the language department

The Liaison Because of the liaisons, ALTEC was able to successfully Contribution launch several Telecommunications for Foreign Language Across the Curriculum (TELFLAC) projects in Business, History, Philosophy and Honors. A side benefit of these projects was that they introduced faculty from different disciplines to each other and helped spread the word on campus about the work that ALTEC is doing.

Our French liaison established an exchange program between the University of Colorado and the University of Valencienes, France. The students were so enthusiastic about using the Internet and fax machine to communicate that they wanted to expand their interactions by visiting each other's country!

Two of our liaisons successfully wrote proposals to US West and CCFLT (Colorado Congress of Foreign Language Teachers) and received grant money for the use of Minitel. Thanks 
to these funds the French faculty have been able to complete Minitel projects and have incorporated the Minitel in most of the first and second year French classes.

The liaisons regularly help us provide workshops/seminars that are specifically designed for the faculty in their departments. These could be anything from how to use the Internet to find information on Peru to bringing in a guest speaker on how to teach language to learning-disabled students.

Last, but perhaps most important, is the liaisons provide valuable information to us about what's happening in the departments and what will happen down the line. They keep us grounded but also get us excited about the possibilities and generate new ideas.

Funding the Positions

Summary
Funding for the liaisons is precarious at best, but we always find a way. The money comes out of our yearly allotted general fund-our operating budget. To get the funds, we plead our case to the dean of our college every year and sometimes twice a year. We feel that the positions are so important that if less funding were available, we would cut elsewhere (such as reducing hours and/or hiring fewer students).

Occasionally we receive money from other sources such as gifts (private, corporate), grants or on-campus special funds. We have investigated the possibility of internships or independent study credit for liaisons, but so far we have not used this option. A few times we have asked a foreign language department for matching funds or other materials such as computers or other equipment (this spring the French/Italian department gave us the money to purchase a Macintosh 8100). For the past few years we have been lobbying for a lab fee for students in first and second year language courses. It looks like this fall it will become reality.

If you plan to try this program, here are a few tips to keep in mind:

- Treat liaisons as professionally as possible. (Give them a desk, access to the office after hours, other "privileges.")

- Treat them as "talent" - a creative resource.

- Give liaisons flexible hours and be considerate of their needs (teaching load, studying, children, etc.).

- Include them in decision making as much as possible. The liaison program has worked extremely well and been enthusiastically accepted,improving relations and communication between ALTEC and the foreign language departments and thus achieving the main goal of the program. 
The format of the original presentation was to share with Presentations participants some of our attempts to stimulate faculty development. During a question and answer session, participants talked about some of their experiences. The goal was to learn from each other. It is our hope that lab directors recognize the need to engage in some creative thinking in this area and then to develop faculty involvement action plans that can be implemented at their local institutions. It is safe to say that no plan will reach all faculty, but progress should be measured by partial successes. To rephrase a bit of common wisdom, "You can't reach all of them all the time, but you can reach some of them some of the time." Faculty, students and lab personnel will all benefit from our efforts in this area.

David Pankratz is the Director of the Language Learning Resource Center, Loyola University Chicago.

Marie Sheppard was the former Editor-in-Chief of the IALL Journal and Director of ALTEC at the University of Colorado at Boulder.

Robin McClanahan is an Editorial Assistant for the IALL Journal and the Office Manager of ALTEC at the University of Colorado at Boulder.

\section{YOUR SOURCE FOR FOREIGN LANGUAGE SOFTWARE}

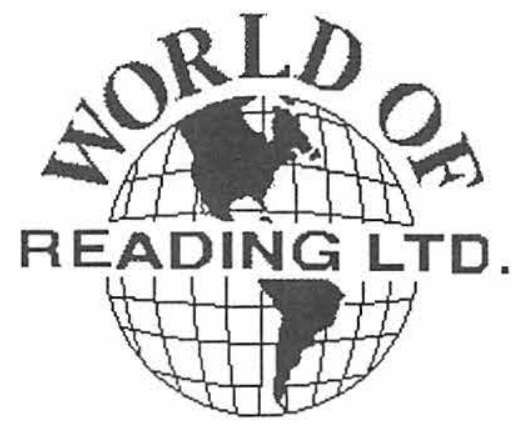

We offer a wide range of software with new programs all the time like Spanish Your Way from Syracuse Language Systems. If you have not seen our 1995-1996 catalogue, you have not seen how competitive our prices are. Call for a catalogue at (404) 233-4042 or (800) 729-3703 or E-mail us at: 74537,3451@comp.com or PolyglotCT@aol.com. 